\title{
Quantitative analysis of fluorescent caspase substrate cleavage in intact cells and identification of novel inhibitors of apoptosis
}

\author{
P Tawa ${ }^{1}, \mathrm{~J} \mathrm{Tam}^{1}$, R Cassady ${ }^{1}$, DW Nicholson ${ }^{1}$ and \\ S Xanthoudakis ${ }^{\star, 1}$ \\ ${ }^{1}$ Department of Biochemistry and Molecular Biology, Merck Frosst Centre for \\ Therapeutic Research, Kirkland, Quebec, Canada, H9H 3L1 \\ * Corresponding author: S Xanthoudakis, Department of Biochemistry and \\ Molecular Biology, Merck Center for Therapeutic Research, P.0. Box 1005, \\ Pointe-Claire-Dorval, Quebec, Canada, H9R 4P8. \\ Tel: 514 428-3461; Fax: 514 428-4900 \\ E-mail: steven_xanthoudakis@merck.com
}

Received 14.7.00; revised 28.8.00; accepted 30.8.00

Edited by G Melino

\begin{abstract}
Caspase activation and proteolytic cleavage of specific target proteins represents an integral step in the pathway leading to the apoptotic death of cells. Analysis of caspase activity in intact cells, however, has been generally limited to the measurement of end-point biochemical and morphological markers of apoptosis. In an effort to develop a strategy with which to monitor caspase activity, early in the cell death cascade and in real-time, we have generated cell lines that overexpress recombinant GFP-based caspase substrates that display a quantifiable change in their spectral properties when cleaved by group II caspases. Specifically, tandem GFP substrates linked by a caspase-sensitive cleavage site show diminished fluorescence resonance energy transfer (FRET), as a consequence of cleavage, due to physical separation of the GFP moieties in apoptotic cells. We have evaluated the influence of different caspasesensitive linkers on both FRET efficiency and cleavage by caspase-3. We also demonstrate that caspase activity as well as inhibition by pharmacological agents can be monitored, with minimal manipulation, in intact adherent cells seeded in a 96-well cell culture dish. Finally, we have adapted this technology to a high throughput screening platform to identify novel small molecule and cell permeable inhibitors of apoptosis. Based on a biochemical analysis of the compounds identified it is clear that this assay can be used to detect drugs which inhibit caspases directly as well as those which target upstream components of the caspase cascade. Cell Death and Differentiation (2001) 8, 30-37.
\end{abstract}

Keywords: apoptosis; caspase activity; GFP

Abbreviations: FRET, fluorescence resonance energy transfer; GFP, green fluorescent protein; PARP, poly-(ADP-ribose)-polymerase; DEVD-CHO, tetrapeptide aldehyde

\section{Introduction}

Apoptosis is characterized by distinct series of morphological and biochemical changes that inevitably result in the death of a cell. ${ }^{1-3}$ Among the key biochemical mediators of apoptosis are a group of proteolytic enzymes known as the caspases, which serve to disrupt normal cellular homeostasis by cleaving specific target proteins with either structural, regulatory or housekeeping functions. ${ }^{4-6}$ The caspases comprise a family of proteins and can be distinguished according to their substrate specificities. ${ }^{7}$ Group II caspases, which include caspases-2, -3 and -7 , are the primary effector caspases and display a preference for substrates containing tetrapeptide recognition motifs of the type DXXD. ${ }^{7}$ Caspase6 , a group III activator caspase based on substrate preference, may also play an effector role and has been shown to lie downstream of caspase-3. ${ }^{8,9}$ All caspases are synthesized as dormant proenzymes and can be rapidly activated through proteolytic maturation. ${ }^{4,5}$ Given their central role as death effector molecules, a great deal of interest has recently focused on the caspases as therapeutic targets for various disease processes (e.g. acute neurodegeneration, cardiac ischemia, hepatic failure). ${ }^{10}$ Unfortunately, methodologies for monitoring caspase activity, at least in the context of cell-based systems, are primarily limited to analyzing downstream biochemical events (i.e. DNA fragmentation, membrane remodeling) that are often several steps removed from the active caspases. ${ }^{11}$ One alternative approach that can be used to circumvent this problem is to provide an endogenous source of recombinant caspase substrate whose cleavage can be easily monitored. GFP-based reporter strategies have been used in numerous cellular systems to monitor transcriptional activation, cellular localization and protein trafficking. ${ }^{12,13}$ Their utility as in vitro substrates for protease assays have also been demonstrated. ${ }^{14-16}$ In the following study, we have exploited recently developed mutants of GFP, ${ }^{12}$ which possess unique spectral characteristics, to generate novel recombinant caspase substrates. These substrates can be used as reporter molecules to directly measure in vivo caspase activity in response to stimuli that induce apoptosis. ${ }^{17,18}$ Caspase activity in this cell-based system is measured as a function of fluorescence resonance energy transfer (FRET) between tandem GFP molecules containing an interposed caspase-3 cleavage site. Furthermore, we have adapted the assay for use as a high throughput screen for the identification of novel inhibitors of apoptosis which inhibit caspases both directly and indirectly.

\section{Results and Discussion}

Recombinant caspase substrates were engineered to be encoded as inducible fusion proteins comprised of tandem 
green fluorescent protein (GFP) molecules tethered by amino acid sequences that are recognized and cleaved by group II caspases (i.e. caspase-3) (Figure 1). ${ }^{7}$ We chose to develop a tetracycline-inducible expression system to circumvent potential problems with non-specific GFP-mediated toxicity due to prolonged overexpression. ${ }^{19}$ The caspase-recognition motif (DEVD) embedded within these fusion proteins was derived from the protease cleavage site identified in poly(ADP-ribose)-polymerase (PARP), a well characterized substrate of caspase- 3 in apoptotic cells. ${ }^{20}$ Furthermore, this site has been defined as the optimal group II caspase cleavage motif on the basis of studies that have examined cleavage of combinatorial fluorogenic tetrapeptide substrate libraries. ${ }^{7}$

The spectral properties (excitation and emission) of the mutant GFP proteins (W1B, Topaz; Aurora Biosciences) used to generate the fusions are well suited for discrimination between the cleaved and uncleaved forms of the protein using standard fluorometry. ${ }^{13} \mathrm{~W} 1 \mathrm{~B}$ has dual excitation (434/452 $\mathrm{nm}$ ) and emission peaks (476/505 nm), while Topaz has excitation and emission maxima of 514 and $527 \mathrm{~nm}$, respectively. In principle, caspase-3-mediated

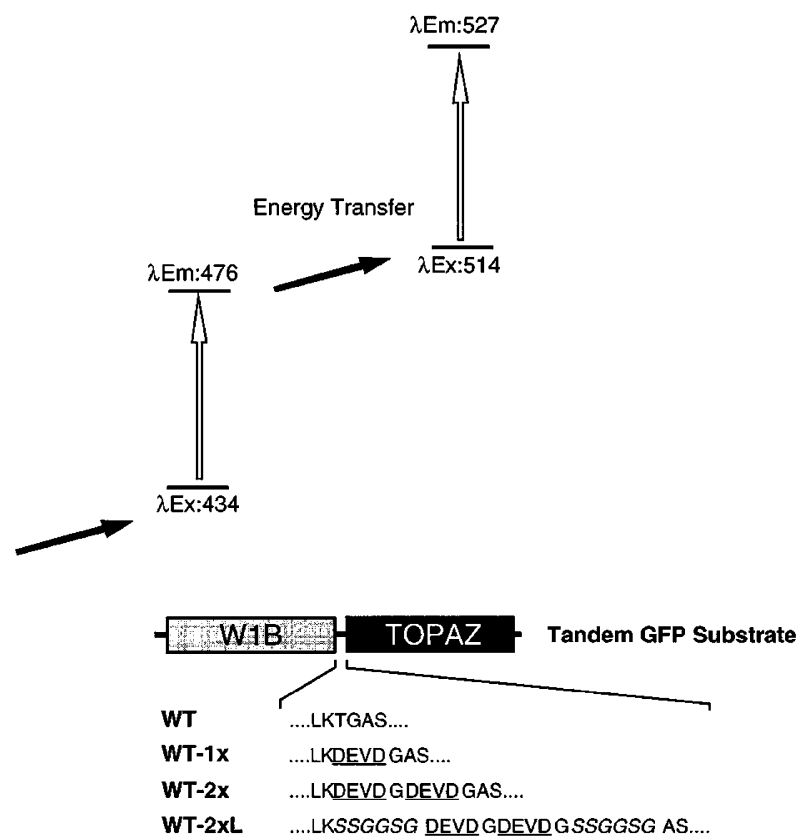

Figure 1 Fluorescence resonance energy transfer between mutant GFP variants in the recombinant group II caspase substrate. Upon excitation of the donor fluorophore (W1B) at $434 \mathrm{~nm}$, its emitted energy $(476 \mathrm{~nm})$ is transferred to the acceptor fluorophore (TOPAZ) and is re-emitted at $527 \mathrm{~nm}$. This energy transfer is dependent on close physical proximity to the two GFP fluorophores. Caspase-mediated cleavage of the linker abrogates energy transfer through separation of the GFP molecules. Outlined below the schematic of the tandem GFP protein is the primary amino acid sequence of the linker for each of the fusion proteins constructed (WT, WT-1x, WT-2x, and WT-2xL). Note that the WT fusion contains a short six amino acid linker lacking a caspase tetrapeptide cleavage motif. The WT-1x and WT-2x proteins contain a single and two tandem group II caspase cleavage motifs (DEVD) within the linker, respectively. WT-2xL contains two tandem DEVD cleavage motifs flanked by six amino acid SG repeats designed to confer flexibility and accessibility to the linker cleavage of these substrates should prevent fluorescence resonance energy transfer (FRET) between linked GFP proteins due to physical separation of the molecules. When excitation occurs at the excitatory wavelength (ex: $434 \mathrm{~nm}$ ) of the donor molecule, cleavage of the substrate can be quantitated as a ratio of excited fluorescence emitted by the acceptor molecule (Topaz, em: $527 \mathrm{~nm}$ ) divided by the fluorescence emitted by the donor molecule (W1B; em: $476 \mathrm{~nm}$ ). In our cell-based assay, an increase in the ratio of emitted fluorescence at these wavelengths (527/476) would reflect an inhibition of caspase activity.

In order to successfully develop this assay various criteria had to be realized. For example, it was necessary to demonstrate that the caspase- 3 cleavage motif embedded within the linker region could be efficiently cleaved by caspase-3 and not impair FRET between the tethered molecules. To this end, several potential linker regions comprising single or tandem DEVD sites were designed in order to optimize both cleavage as well as FRET efficiency. We also generated a construct, designated WT-2xL, in which tandem DEVD sites were flanked by hinge regions, rich in glycine and serine residues, that could impart flexibility to the GFP fusion protein and promote energy transfer. ${ }^{21-23}$ Figure 2 shows a direct correlation between the length of the linker region examined and the efficiency of FRET in transfected Hela cells overexpressing the fusion proteins. As the length of the linker separating the GFP molecules was increased, a corresponding decrease in FRET efficiency was observed. Energy transfer was more efficient in fusions containing the single (WT-1x) versus the tandem (WT-2x) DEVD motif. Interestingly, inclusion of a flexible hinge region within the linker offered no particular advantage, but instead served to diminish FRET efficiency of the WT-2xL fusion protein relative to its parental form (WT-2x).

The sensitivity of the tandem GFP substrates to cleavage by caspases was examined initially using $\left[{ }^{35} \mathrm{~S}\right]-$ Met radiolabeled proteins translated in wheat germ lysates. The proteins were incubated in vitro with increasing concentrations of purified recombinant caspase- 3 and the cleavage products were resolved by polyacrylamide gel electrophoresis and quantitated by autoradiographic analysis of the gels. A comparison of the single (WT-1x) versus the dual DEVD-containing substrates (WT-2x and WT-2xL) showed the latter to be cleaved approximately fourfold more efficiently as estimated by their respective $\mathrm{K}_{\mathrm{cat}} / \mathrm{K}_{\mathrm{m}}$ values (Figure 3 ). This result is consistent with previous data using other recombinant caspase substrates in which DEVD motifs have been artificially introduced (unpublished observations). This also demonstrates that, by multimerizing DEVD motifs, it is possible to generate novel substrates that are cleaved as efficiently as authentic group II caspase substrates (e.g. PARP, U1-70 kDa and DNA-PKCs). ${ }^{24} \mathrm{~A}$ comparison of the cleavage efficiency between the WT-2x and WT-2xL constructs, both of which contain two DEVD motifs, showed a modest increase $(0.5$-fold) in favor of the longer WT-2xL construct (see Figure 1 for a comparison of linker composition). However this increase was only marginal as compared to the fourfold gain in cleavage efficiency attained by increasing the number of DEVD 
A

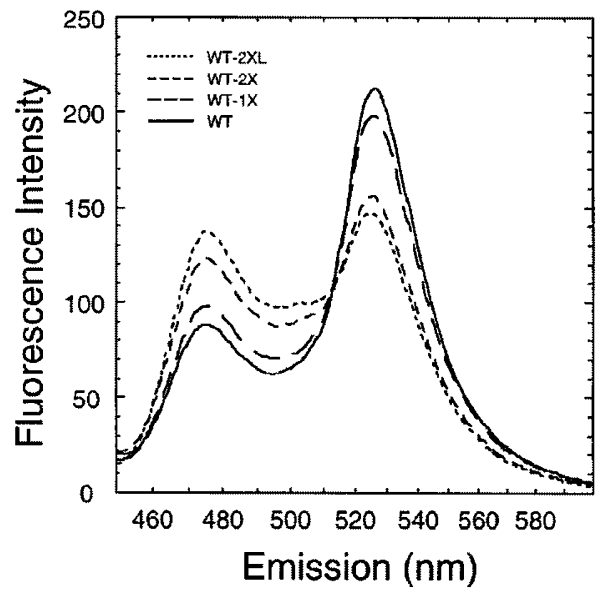

B

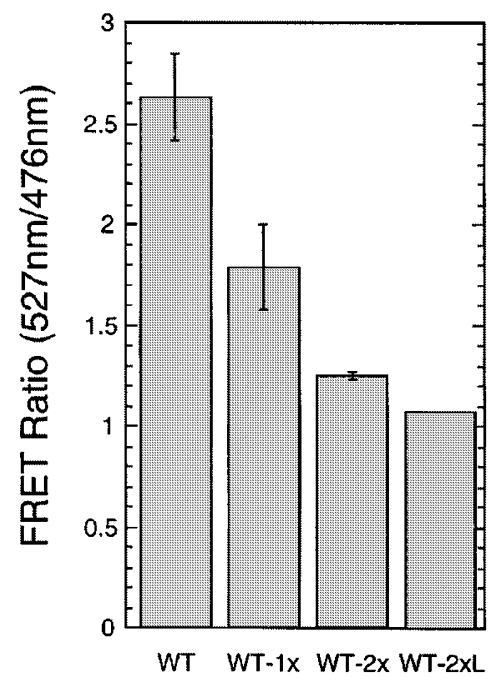

Figure 2 FRET efficiency is a function of the linker length. Lysates from Hela cells transfected transiently with constructs encoding the WT, WT-1x, WT-2x, or WT-2xL fusion proteins were assayed for fluorescence. (A) The emission scan $(450-600 \mathrm{~nm})$ of the lysates following excitation at $434 \mathrm{~nm}$. (B) Measurement of FRET (expressed as the ratio of the fluorescence emitted by the acceptor (TOPAZ, $527 \mathrm{~nm}$ ) divided by the fluorescence emitted by the donor (W1B, $476 \mathrm{~nm}) n=2)$ )

cleavage sites. Nonetheless, increasing the linker length does appear to have an augmentative effect on cleavability. To compare the efficiencies with which these fusion proteins could be cleaved by caspases in intact cells, we stimulated Hela cells transfected with the various constructs to undergo apoptosis and analyzed the cleavage products by immunoblot analysis using polyclonal anti-GFP antibodies (Figure 4). Several studies have previously demonstrated that staurosporine induces proteolytic activation of caspase-3 in Hela cells. ${ }^{25,26}$ In contrast to the negative influence on FRET efficiency conferred by increasing the number of DEVD sites in the linker region separating the two GFP molecules, fusion proteins harboring tandem DEVD motifs were cleaved more efficiently following staurosporine treatment. Furthermore,

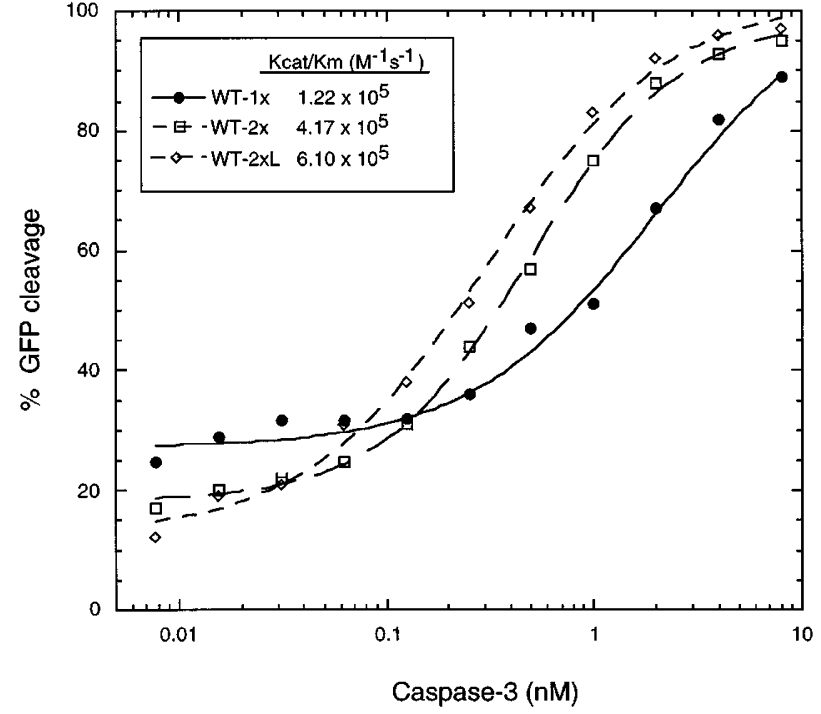

Figure 3 Tandem GFP substrates containing multiple DEVD motifs are cleaved more efficiently by caspase- 3 . In vitro translated and $\left[{ }^{35} \mathrm{~S}\right]$ methionine-labeled WT-1x, WT-2x and WT-2xL proteins were incubated with varying concentrations of purified recombinant caspase- 3 for $1 \mathrm{~h}$ at $37^{\circ} \mathrm{C}$. Cleaved proteins were resolved by SDS polyacrylamide gel electrophoresis and quantitated by autoradiography and scanning densitometry of the gels. The reactions were carried out using concentrations of substrate well below $\mathrm{K}_{\mathrm{m}}$, where the appearance of the product is a first-order process. Values for $\mathrm{k}_{\text {cat }} / \mathrm{K}_{\mathrm{m}}$ were calculated from the relationship $S_{t} / S_{0}=e^{- \text {kobs }^{*} t}$ where $S_{t}$ is the concentration of the substrate remaining at time $t, S_{0}$ is the initial substrate concentration, and $\mathrm{k}_{\mathrm{obs}}=\mathrm{k}_{\text {cat }}{ }^{*}[$ enzyme $] / \mathrm{K}_{\mathrm{m}}$

cells transfected with the parental construct lacking a caspase-3 cleavage site (WT) failed to induce proteolytic cleavage of the fusion protein in response to apoptosis. In addition, cleavage of the DEVD-containing fusion proteins was dramatically attenuated by incubating staurosporinetreated cultures with zVAD-fmk, an irreversible pancaspase peptide inhibitor. This data confirms that recombinant GFP substrates could be used to monitor activation as well as inhibition of group II caspases in cells. Interestingly, in these experiments the FRET ratios and protein levels obtained with DEVD-containing substrates were slightly elevated in control cultures that were transfected in the presence of ZVAD-fmk, but in the absence of staurosporine. The enhanced FRET observed in these cultures is attributable to their healthier metabolic state relative to the transfected cultures that did not undergo any drug treatment. We have noted in the past that the transfection procedure alone induces some apoptosis, which thereby results in partial substrate cleavage as well as a diminished translational capacity. This cleavage is in fact reflected in the immunoblot shown in Figure 4a (WT-2x panel, 1st lane). However, as expected this effect is not seen with stable lines that overexpress the tandem GFP fusion protein.

To determine whether inhibition of caspase cleavage could cause a measurable and dose-dependent change in FRET, we titrated caspase inhibition by zVAD-fmk in cultured Hela cells stably overexpressing the WT-1x construct (Figure 5). We chose this fusion construct for 
A

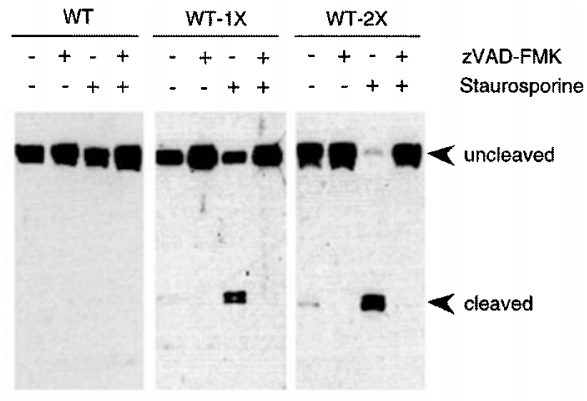

B

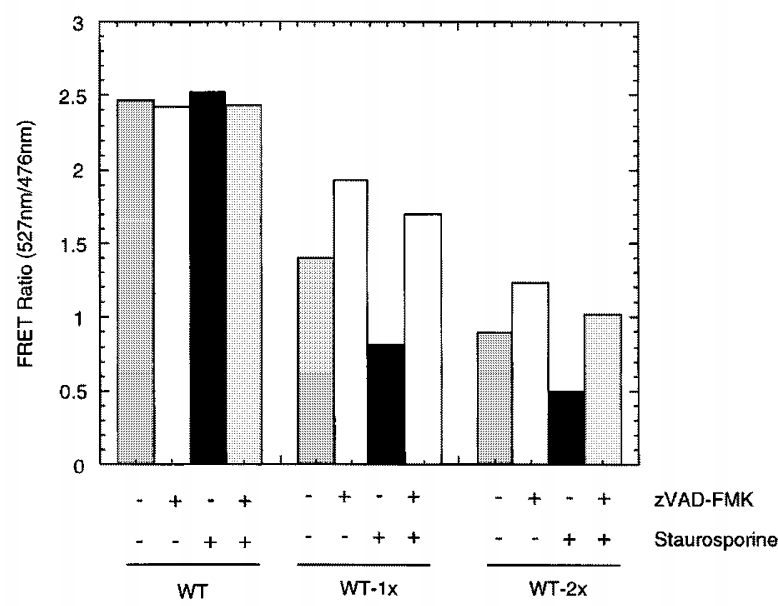

Figure 4 Apoptosis results in cleavage of DEVD-containing tandem GFP substrates. (A) Western blot analysis of the tandem GFP substrates in lysates prepared from Hela cells transfected with the WT, WT-1x, or WT-2x constructs. Apoptosis was induced by treatment of the cells for $4 \mathrm{~h}$ with $1 \mu \mathrm{M}$ staurosporine. (B) FRET measurements from untreated cells and cells treated in the presence $(+)$ or absence $(-)$ of staurosporine and a pan caspase inhibitor (zVAD-fmk). Each of the samples shown in B corresponds to the same lysates used for Western analysis in $\mathbf{A}$. The data represents the average of two transfection experiments from which the lysates were pooled. Note that FRET is diminished in apoptotic extracts containing caspase-3 sensitive tandem GFP substrates only

analysis because it represented a reasonable compromise between energy transfer efficiency and cleavability as a substrate (Figures 2 and 3 ). Caspase inhibition was examined using intact cells plated in a 96-well culture dish. The fluorometer, equipped with the appropriate filter sets to detect FRET, was calibrated to read fluorescence emitted from intact cells lying on the surface of the plate. Confocal microscopy revealed a homogeneous distribution of the substrate throughout the cytoplasm and nucleus (data not shown). The intracellular concentration of GFP substrate was estimated to be approximately $2 \mu \mathrm{M}$ based on immunoblotting experiments where the amount of substrate in the lysate was extrapolated from a titration of the recombinant protein (data not shown). Following treatment with staurosporine alone or in combination with different concentrations of the inhibitor (zVAD-fmk), the cells were examined by fluorescence analysis. The data in Figure 5 shows that treatment of WT-1x-expressing cells with increasing concentrations of zVAD-fmk resulted in a

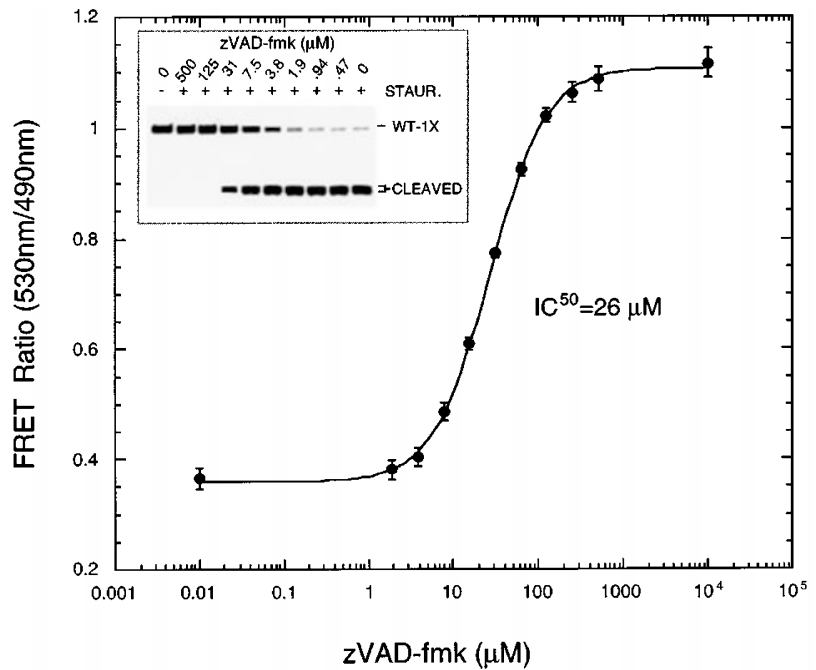

Figure 5 Direct fluorometric measurement of caspase inhibition in intact cells. Hela cells (Clone HETON-WT-1x-57) overexpressing the WT- $1 x$ tandem GFP substrate were treated simultaneously with staurosporine to induce apoptosis and varying concentrations of zVAD-fmk for $4 \mathrm{~h}$. Cells were assayed for FRET $(530 / 490 \mathrm{em}$.) after exchanging the media for PBS. The 0.01 and $10000 \mu \mathrm{M}$ titration points represent values for the maximum (DMSO vehicle alone) and minimum (staurosporine alone) FRET ratios obtained, respectively. The data represented is from three experiments (mean \pm S.E.). In each experiment four to eight replicate wells were assayed for every titration point. The inset shows an immunoblot of the corresponding cleavage of the tandem GFP protein as a function of inhibitor concentration

concomitant and dose-dependent increase in WT-1xderived FRET $\left(\mathrm{IC}_{50}=26 \mu \mathrm{M}\right)$. In addition, the FRET data correlated well with GFP substrate cleavage as determined by immunoblot analysis (Figure 5, inset). The doseresponse curve for inhibition is similar to that obtained when assaying other biochemical markers of apoptosis in Hela cells, including DNA fragmentation $\left(\mathrm{IC}_{50}=11 \mu \mathrm{M}\right)$ and PARP cleavage $\left(\mathrm{IC}_{50}=28 \mu \mathrm{M}\right)$, demonstrating that quantitation can be performed directly on cells without a need for further time-consuming manipulation (e.g. cell harvesting, lysate preparation, immunoassay).

To explore further the utility of the tandem GFP assay as a high throughput screening methodology for identifying caspase inhibitors, we tested duplicate sets of 96-well drug plates containing either single compounds or mixtures of 10 compounds per well. The final concentration of each drug in these plates ranged between 400-600 $\mu \mathrm{M}$. Pre-screening of these plates revealed the absence of caspase inhibitors among the collection of test compounds (data not shown). In order to demonstrate that caspase inhibitors would have been detected, had they been present among these plates, we chose to supplement individual wells with different concentrations of a known caspase inhibitor (zVAD-fmk). Furthermore, to avoid any bias in the interpretation of the data, the experiment was performed blindly, such that the location of individual wells containing zVAD-fmk was not revealed until the experiment was completed. In these experiments, two wells in each plate were randomly supplemented with three different concen- 
trations of zVAD-fmk $(2.5,25$ and $250 \mu \mathrm{M})$ and each plate was assayed in duplicate. The screening results are shown in Figure 6, where $(A)$ and $(B)$ represent plate arrays containing the single compounds and drug mixtures, respectively. An examination of the data showed that, regardless of the plate format, duplicate wells containing either 25 or $250 \mu \mathrm{M} z V A D$-fmk were readily identified. As expected, zVAD-fmk could not be detected at a concentration $(2.5 \mu \mathrm{M})$ which fails to inhibit cleavage of the tandem
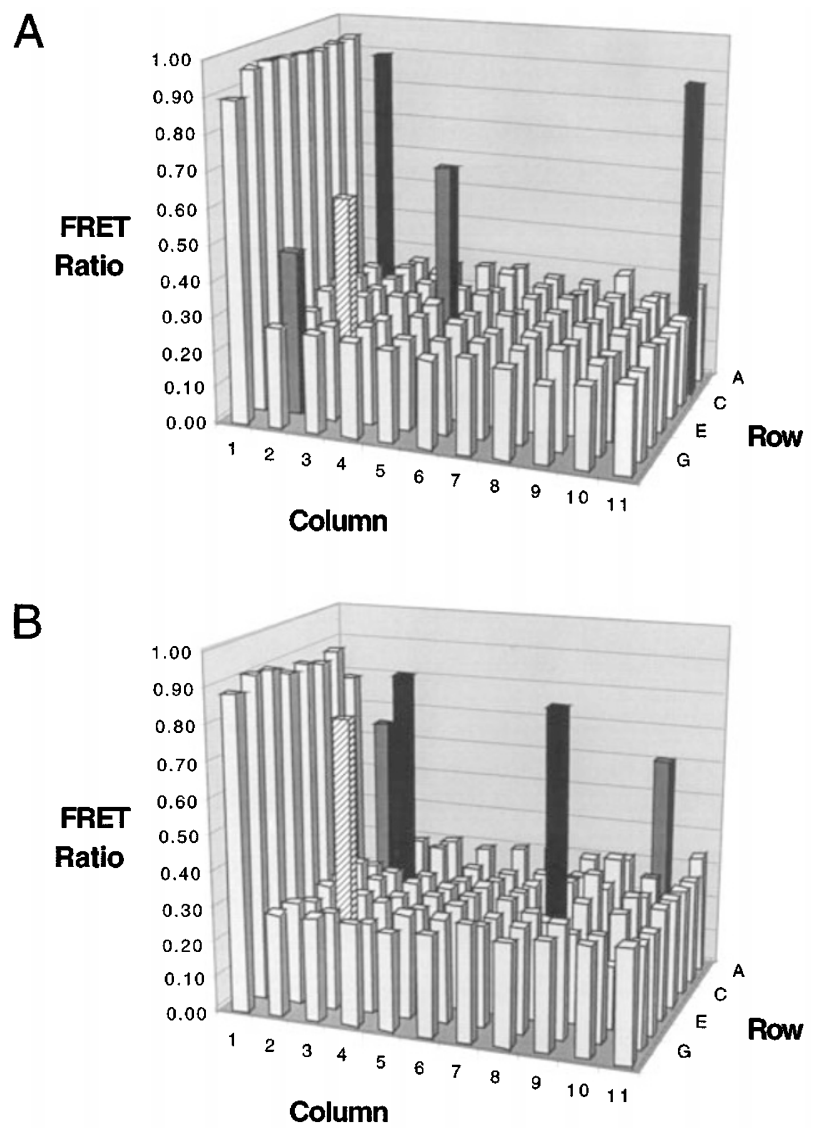

Figure 6 High throughput detection of caspase inhibitors in multiwell plates containing either single compounds (A) or drug mixtures (10 compounds/well) (B). Duplicate 96-well plates were co-treated with staurosporine and drug(s) for $4 \mathrm{~h}$. Three concentrations of zVAD-fmk $(2.5,25$ and $250 \mu \mathrm{M})$ were randomly added to two wells in each plate. The experiment was performed blindly, such that the well location of zVAD-fmk was not revealed until the data was processed. Similar data was obtained for the duplicate plates. The black and gray bars indicate the position of the wells containing 250 and $25 \mu \mathrm{M}$ zVAD$\mathrm{fmk}$, respectively. False-positive hits are indicated by the striped bars. Column 1 (rows $\mathrm{A}-\mathrm{H}$ ) represents uninduced nonapoptotic control wells
GFP substrate (see Figure 5). In one of the plates containing individual compounds, a single well (coordinates G3) produced a positive signal that was not attributable to the presence of zVAD-fmk. This sample, however, represented a false-positive result as it did not register as a hit on a duplicate plate. Only one additional false-positive hit, at the same well position (coordinates G3), was detected on the plate containing the drug mixtures. Although this sample scored as a positive hit on duplicate plates, the fluorescence emission values recorded at both the 490 or $530 \mathrm{~nm}$ wavelengths were far in excess of the maximum emission values obtained from the control wells, indicating that this false-positive hit represented a highly fluorescent compound(s). Coincidentally this compound also gave a fluorescent ratio of greater than 0.3. Finally, while the false-positive hit rate was very low $(0.1-$ $1.0 \%$, it is important to note that both false-positive hits detected in our assay could have easily been filtered out through the use of data analysis algorithms designed to flag such hits. We have also used this assay to screen another 20 test plates derived from an alternate natural products collection. Each well of these plates contains up to several hundred distinct compounds of unknown identity. In this screen the observed hit rate was $0.5 \%$, which with respect to deconvolution and follow-up, represents a very manageable number of hits. Also, all initial positive hits were confirmed by a second round of screening.

More recent screens using sample collections comprised of compounds with known structure have like-wise been successful in identifying small molecule inhibitors of apoptosis. The advantage of our particular cell-based assay is that it permits detection of caspase inhibitors as well as inhibitors which act proximally in the apoptotic cascade. Two novel compounds identified, MF425 and MF432, with molecular masses of 425 and 432 Daltons, respectively, appear to segregate into functionally distinct classes, based on their ability to attenuate apoptosis via direct or indirect inhibition of caspases. A comparison of the inhibition profile of these compounds is shown in Table 1. Both compounds identified were tested for activity in different cell-based assays and also against various recombinant caspases representing the three major subclasses [caspase-1 (group 1), caspases-3 and -7 (group II), caspase-8 (group III)]. A second cell-based assay, used to specifically evaluate inhibition of apoptosis with other markers, involved measurement of staurosporine-induced nucleosome fragmentation in Hela cells using an ELISA (CDEIA). An analysis of the data indicates that while both compounds were potent in each of the cell-based assays,

Table 1 Inhibition profile of novel inhibitors of apoptosis

\begin{tabular}{|c|c|c|c|c|c|c|c|c|}
\hline \multirow[b]{2}{*}{ Compound } & \multirow{2}{*}{$\begin{array}{c}\text { \% Inhibition } \\
\text { (@20 } \mu \mathrm{M}) \\
\text { FRET }\end{array}$} & \multicolumn{6}{|c|}{$\mathbf{I C}_{50}(\mu \mathrm{M})$} & \multirow[b]{2}{*}{ Reversible } \\
\hline & & Hela* & CGN & Casp1 & Casp3 & Casp7 & Casp8 & \\
\hline MF432 & 17 & 18 & - & $>200$ & 18 & 98 & $>200$ & Yes \\
\hline MF425 & 69 & 4 & $2.2^{\mathrm{a}} / 1.6^{\mathrm{b}}$ & $>200$ & $>200$ & $>200$ & $>200$ & - \\
\hline
\end{tabular}

${ }^{\mathrm{a}} \mathrm{IC}_{50}$ in cerebellar granule neurons treated with etoposide $(n=4) ;{ }^{\mathrm{b}} \mathrm{IC}$. in cerebellar granule neurons deprived of $\mathrm{K}^{+}$serum $(n=4)$; ${ }^{\star} \mathrm{Apoptosis}$ in $\mathrm{Hela}$ cells was induced with staurosporine $(n=4)$ 
only MF432 was capable of directly inhibiting caspase activity. In addition, MF432 was selective against the group II enzymes and in particular caspase-3 (caspase-3, $\mathrm{IC}_{50}=18 \mu \mathrm{M}$ and caspase-7, $\left.\mathrm{IC}_{50}=98 \mu \mathrm{M}\right)$. The observed specificity of MF432 is consistent with the caspase selectivity of the GFP reporter substrate. To characterize this effect on caspase- 3 in more detail, additional enzyme analysis was performed to determine whether MF432 functioned as a time-dependent or irreversible inhibitor. Dilution of the inhibited enzyme in a buffer lacking the drug, resulted in a rapid recovery of the catalytic activity, suggesting that the compound acted by a reversible mechanism (Figure 7). This effect was not seen with the negative control, a tetrapeptide aldehyde (DEVD-CHO), which because of its slow off-rate $\left(k_{\text {off }}=4.5 \times 10^{-5} \mathrm{~s}^{-1}\right)$, mimics an irreversible inhibitor.

Finally, the lack of an effect of MF425 on caspase activity in vitro suggests that its mechanism of action is likely to involve an upstream component of the caspase cascade. We have found that this compound is also potent against apoptosis in different cell lines with varied lineage, including T-cells $\left(\mathrm{IC}_{50}=8 \mu \mathrm{M}\right)$ as well as mouse cerebellar granule neurons. With respect to primary neurons, MF425 is effective at protecting against both etoposide-induced cell death $\left(\mathrm{IC}_{50}=2.2 \mu \mathrm{M}\right)$ as well as cell death induced by $\mathrm{K}^{+}$ serum deprivation $\left(\mathrm{IC}_{50}=1.6 \mu \mathrm{M}\right)$ (Figure 8). Both these death-inducing stimuli, in mouse cerebellar granule neurons, have been shown to be dependent on activation of the group II caspase pathway ${ }^{27}$ (and unpublished observations). Although the target of MF425 has yet to be identified, the results clearly demonstrate that it is possible to modulate apoptosis at different steps along the pathway. This further implies that there are multiple target opportunities for therapeutic intervention into diseases and injuries characterized by inappropriate apoptosis.

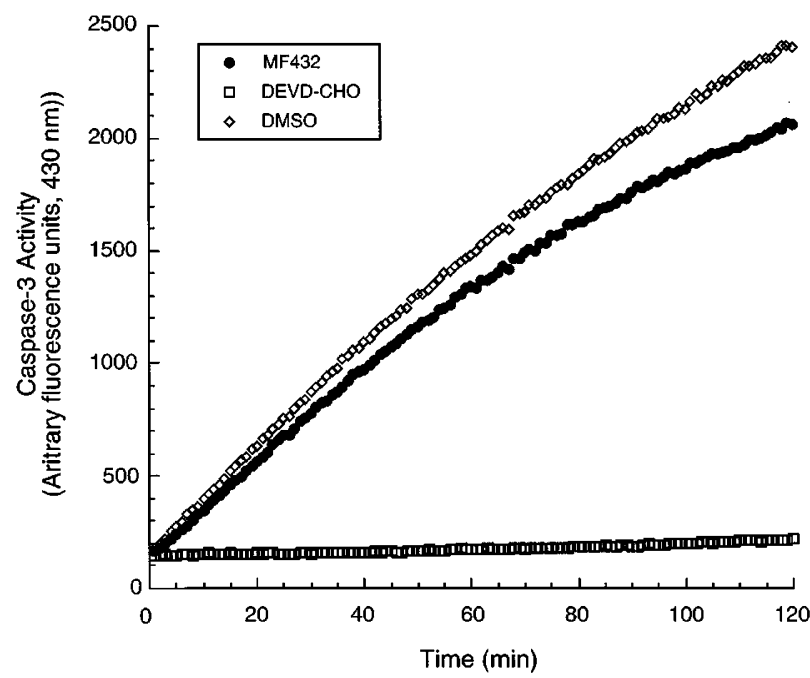

Figure 7 MF432 is a reversible inhibitor of caspase-3. Purified recombinant caspase- $3(11.8 \mathrm{nM})$ was preincubated with $300 \mu \mathrm{M}\left(16 \times \mathrm{IC}_{50}\right) \mathrm{MF} 432,250 \mathrm{nM}$ $\left(10 \times I_{50}\right)$ DEVD-CHO or DMSO (vehicle) for $1 \mathrm{~h}$ at room temperature. The preincubated inhibitor-enzyme mixture was then diluted 100 -fold into buffer containing $10 \mu \mathrm{M}$ DEVD-AMC and cleavage of the fluorogenic substrate monitored in a fluorometer for $2 \mathrm{~h}$ at room temperature

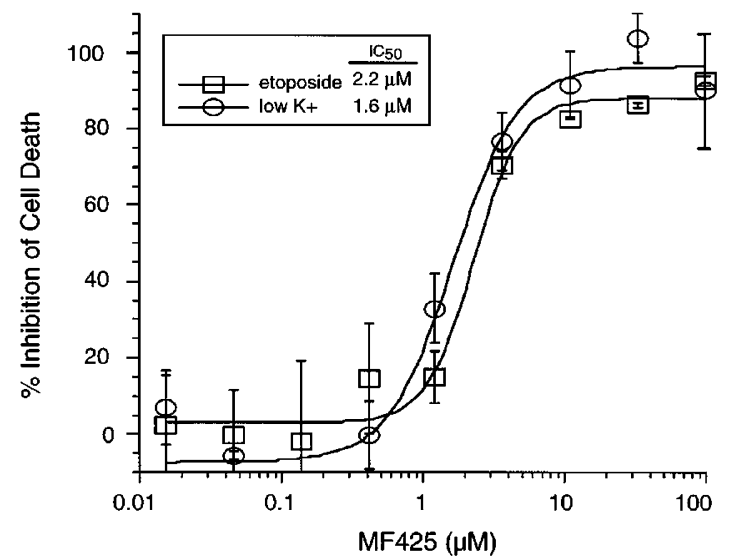

Figure 8 Inhibition of neuronal cell death by MF425. Cerebellar granule neurons from 7 day-old mice were stimulated to undergo cell death by treatment with $50 \mu \mathrm{g} / \mathrm{ml}$ etoposide for $24 \mathrm{~h}$ or by treatment with medium containing low $\mathrm{K}^{+}(5 \mathrm{mM})$ in the absence of serum for $8 \mathrm{~h}$. Upon stimulation the cultures were cotreated with MF425 at various concentrations. At the end of the incubation period the cells were lysed and the presence of apoptotic nucleosomal fragments was assayed by ELISA. The data are expressed as percentage of inhibition of death seen in the absence of inhibitor $(n=4)$

Taken together our results support the use of recombinant intracellular substrates as a means by which to rapidly assay caspase activity and apoptosis in the context of an intact cellular environment. Our data validates the technology as an effective screening tool for novel inhibitors of apoptosis. The ability to perform this cell-based assay in a high throughput multi-well format further emphasizes its usefulness for drug discovery. Although we have not used the assay to screen for agents that induce apoptosis, this technology should be equally amenable to the identification of novel anti-cancer drugs. Another important advantage of this system is that it offers the opportunity to perform real-time kinetic analysis of substrate cleavage in vivo. In addition, the tandem GFP system described here should be readily adaptable for use with additional protease targets.

\section{Materials and Methods}

\section{Constructs}

The W1B GFP mutant was amplified by polymerase chain reaction (PCR) as an EcoRI/W1B/Afll/Agel fragment from pRSETA-hW1B (Aurora Biosciences). A Kozak consensus (gccgccaccatgg) was engineered into the start methionine of $\mathrm{W} 1 \mathrm{~B}$ and the stop codon was deleted. ${ }^{28}$ Topaz was amplified by PCR as an Agel/Nhel/TOPAZ/ $B a m H I$ fragment from pRSETA-TOPAZ (Aurora Biosciences). The start methionine of Topaz was deleted. W1B and Topaz were coligated into the EcoRI/BamHI sites of pIRES1neo (Clontech) as EcoRI/ Agel and $A g e l / B a m H I$ fragments respectively to generate pIRES1neoWT. This created a tandem fusion between of W1B and TOPAZ separated by a six amino acid linker encoded by the Aflll/Agel/Nhel sites. pIRES1neo-WT-1x, pIRES1neo-WT-2x, and pIRES1neo-WT$2 x L$ were generated by ligation of synthetic oligonucleotides encoding DEVD linker sequences into the $A f l l /$ Nhel sites of the parental pIRES1neo-WT plasmid. 


\section{Transfections}

Hela cells $\left(7.5 \times 10^{5}\right)$ were subcultured into $60 \mathrm{~mm}$ tissue culture dishes and transfected the following day with $2.5 \mu \mathrm{g}$ of plasmid DNA using the Lipofectamine Plus reagent (Life Technologies). Cells were allowed to express the GFP fusions for a further $48 \mathrm{~h}$ prior to analysis. To determine maximum possible FRET efficiency, zVAD-fmk $(100 \mu \mathrm{M})$ (Enzyme Systems Products) was included in the media during the transfection procedure and maintained for the $48 \mathrm{~h}$ in order to inhibit caspase activity that is generated as a consequence of the transfection. In the Western blotting experiments, zVAD-fmk was included in the media as described above. For induction of apoptosis, cells were treated with staurosporine $(1 \mu \mathrm{M})$ for $4 \mathrm{~h}$ following the initial $48 \mathrm{~h}$ expression period.

\section{Preparation of lysates}

Hela cells from $60 \mathrm{~mm}$ tissue culture dishes were scraped into their growth media and pelleted at $2000 \times g$ for $10 \mathrm{~min}$ at $4^{\circ} \mathrm{C}$. Cell pellets were rinsed with $1 \mathrm{ml}$ cold PBS and repelleted as described above. One hundred microliters of TET buffer ( $50 \mathrm{mM}$ Tris, $\mathrm{pH} 7.5 / 2 \mathrm{mM}$ EDTA $/ 1 \%$ Triton $\mathrm{X}-100$ ) was used to disrupt the cell pellets and the resulting lysates were cleared by centrifugation at $10000 \times g$ for $10 \mathrm{~min}$ at $4^{\circ} \mathrm{C}$.

\section{In vitro FRET measurements}

Lysates corresponding to $1 \mathrm{mg}$ of total protein (transient transfections) or complete lysate (stable cell lines) were diluted to $1 \mathrm{ml}$ with $50 \mathrm{mM}$ Tris, $\mathrm{pH} 7.5$ and the fluorescence was measured using a Perkin Elmer LS 50B fluorometer. The ratio of the intensity of the $527 \mathrm{~nm}$ emission peak (TOPAZ) over the intensity of the $476 \mathrm{~nm}$ emission peak (W1B) after excitation at $434 \mathrm{~nm}$ (W1B) provided us with a measurement of the level of FRET occurring between the two GFP chromaphores. No fluorescence was detected in Hela cells transfected with the empty pIRES1neo vector.

\section{In vitro cleavage of tandem GFP substrates}

The WT-1x, WT-2x and WT-2xL coding sequences were subcloned from pIRES1neo into pcDNA3.1 (-) (Invitrogen) using existing EcoRI/ BamHI sites. [ ${ }^{35} \mathrm{~S}$ ]-methionine-labeled WT-1x, WT-2x and Wt-2xL proteins were generated using a coupled T7-wheat germ in vitro transcription/translation system (Promega). pcDNA3.1(-) constructs $(2 \mu \mathrm{g})$ were incubated with $8 \mu \mathrm{l}$ of $\left.{ }^{35} \mathrm{~S}\right]$-methionine $(10 \mu \mathrm{Ci} / \mu \mathrm{l})$ (Amersham) and $2 \mu \mathrm{l} \mathrm{RNAsin} \mathrm{(40} \mathrm{U/ \mu l)} \mathrm{(Boehringer} \mathrm{Mannheim)} \mathrm{in} \mathrm{a}$ total of $100 \mu \mathrm{l}$ of wheat germ lysate for $45 \mathrm{~min}$ at $30^{\circ} \mathrm{C}$. Cleavage of radiolabeled WT-1x, WT-2x and WT-2xL protein was performed by incubation with purified recombinant caspase-3 in a final volume of $10 \mu$ l of cleavage buffer (50 mM HEPES/KOH (pH 7.0), 2 mM EDTA, $0.1 \%$ CHAPS, $10 \%(w / v)$ glycerol, $10 \mathrm{mM}$ DTT) for $1 \mathrm{~h}$ at $37^{\circ} \mathrm{C}$. The reactions were terminated by addition of SDS sample buffer followed by heating to $95^{\circ} \mathrm{C}$ for $5 \mathrm{~min}$. The cleavage products were resolved by SDS-polyacrylamide gel electrophoresis and visualized by autoradiography. Autoradiograms were quantitated by laser scanning densitometry.

\section{Western blots}

Crude cell lysates $(15 \mu \mathrm{g})$ prepared from cultures cells (transiently transfected or stable cell lines) were resolved on 10-20\% Tris-glycine SDS gels and transferred to nitrocellulose membranes as previously described. ${ }^{29}$ Immunoblot analysis was performed using A 1:500 dilution of a rabbit polyclonal anti-GFP antibody (Clontech). A 1:3000 dilution of donkey anti-rabbit peroxidase (Amersham) was used as the secondary antibody. Protein bands were visualized by ECL detection (Amersham) and autoradiography.

\section{Generation of stable cell lines and 96-well plate assays}

To generate stable cell clones capable of high level expression of the tandem GFP substrate a tetracycline-inducible expression system was used (Clontech). Following cotransfection of Hela Tet-On cells (Clontech) with pTRE-WT-1x and pTK-Hyg (Clontech) in a $60 \mathrm{~mm}$ dish, the cells were grown for a further $48 \mathrm{~h}$ before being subcultured into $100 \mathrm{~mm}$ dishes in the presence of $150 \mu \mathrm{g} / \mathrm{ml}$ hygromycin. Pooled hygromycin-resistant colonies were treated with $2 \mu \mathrm{g} / \mathrm{ml}$ doxycycline for $48 \mathrm{~h}$ to induce expression of the WT-1x fusion protein. Fluorescent clones were individually isolated into a 96-well plate using fluorescence activated cell sorting (FACS). One cell clone, HETONWT-1x-57, was chosen for further analysis and was plated into a Costar black-walled 96-well clear-bottomed plate at a density of 4000 cells/well in the presence of $2 \mu \mathrm{g} / \mathrm{ml}$ doxycycline. After 2 days of incubation, the media was replaced with fresh media containing doxycycline (200 $\mu \mathrm{l} /$ well). Staurosporine and varying concentrations of zVAD-fmk were co-administered to the cells (1.5\% final DMSO) and allowed to incubate for $4 \mathrm{~h}$. The media was subsequently exchanged for PBS and the fluorescence from intact cells measured using a 96well fluorometer (Perceptive Biosystems Cytofluor) equipped with the appropriate filter sets (420/50ex, 490/40em, and 530/25em). For the screening experiments that were performed using either the single compounds or drug mixtures, two wells in each 96-well plate were randomly supplemented with three different concentrations of zVADfmk $(2.5,25$ and $250 \mu \mathrm{M})$ and each plate was assayed in duplicate. The experiment was performed blindly, in that the well location of zVAD-fmk was not revealed until the data analysis was completed. Screening of plates from the known sample and natural products collections was performed as described above. A positive hit is one that showed $\geqslant 50 \%$ inhibition of GFP FRET. All positive hits were retested to confirm their inhibitory activities.

The cell death ELISA used for analysis of nucleosomal DNA fragmentation was performed in a 96-well plate using a commercially available kit according to the manufacturer's recommendations (Boehringer Mannheim). Primary cerebellar granule neurons were prepared as described ${ }^{27}$ from 7-day-old mice and cultured in vitro for 1 week prior to treatment with $50 \mu \mathrm{g} / \mathrm{ml}$ etoposide at $37^{\circ} \mathrm{C}$ for $24 \mathrm{~h}$ or K $\mathrm{K}^{+}$ serum deprivation at $37^{\circ} \mathrm{C}$ for $8 \mathrm{~h}$. The latter treatment was carried out by replacing the existing culture medium (MEM) with medium containing low $\mathrm{K}^{+}(5 \mathrm{mM})$ and no serum. The presence of nucleosomal DNA fragments in lysates prepared from dying cells was assayed by ELISA as described above.

\section{Caspases and enzyme assays}

Recombinant caspases (-1, -3, -7, and -8) were assayed for inhibition in vitro using a fluorogenic tetrapeptide (DEVD-amino methyl coumarin (AMC)) substrate as described previously. ${ }^{30}$ Kinetic measurements of enzyme activity were obtained on a 96-well fluorometer (Perseptive Biosystems Cytofluor). For the reversibility assays purified recombinant caspase-3 $(11.8 \mathrm{nM})$ was preincubated with $300 \mu \mathrm{M} \mathrm{MF} 432$, $250 \mathrm{nM}$ DEVD-CHO or vehicle (DMSO) alone in a CHEG buffer (50 mM HEPES, pH 7.5, 2 mM EDTA, 0.1\% CHAPS, $5 \mathrm{mM}$ reduced glutathione (GSH), $5 \%$ glycerol) for $1 \mathrm{~h}$ at room temperature. The preincubated inhibitor-enzyme mixture was then diluted 100 -fold into a solution of CHEG buffer containing $10 \mu \mathrm{M}$ DEVD-AMC and cleavage 
of the fluorogenic substrate monitored in a fluorometer for $2 \mathrm{~h}$ as indicated above. ${ }^{30}$

\section{References}

1. Kerr JF, Wyllie AH and Currie AR (1972) Apoptosis: a basic biological phenomenon with wide-ranging implications in tissue kinetics. Br. J. Cancer 26: $239-257$

2. Vaux DL, Haecker G and Strasser A (1994) An evolutionary perspective on apoptosis. Cell 76: 777-779

3. Steller H (1995) Mechanisms and genes of cellular suicide. Science 267: 14451449

4. Thornberry NA and Lazebnik Y (1998) Caspases: enemies within. Science 281: 1312-1316

5. Thornberry NA (1997) The caspase family of cysteine proteases. Br. Med. Bull. 53: $478-490$

6. Nicholson DW and Thornberry NA (1997) Caspases: killer proteases. Trends Biochem. Sci. 22: 299-306

7. Thornberry NA, Rano TA, Peterson EP, Rasper DM, Timkey T, Garcia-Calvo M, Houtzager VM, Nordstrom PA, Roy S, Vaillancourt JP, Chapman KT and Nicholson DW (1997) A combinatorial approach defines specificities of members of the caspase family and granzyme B. Functional relationships established for key mediators of apoptosis. J. Biol. Chem. 272: 17907-17911

8. Hirata H, Takahashi A, Kobayashi S, Yonehara S, Sawai H, Okazaki T, Yamamoto K and Sasada M (1998) Caspases are activated in a branched protease cascade and control distinct downstream processes in Fas-induced apoptosis. J. Exp. Med. 187: 587-600

9. Kawahara A, Enari M, Talanian RV, Wong WW and NagataS (1998) Fas-induced DNA fragmentation and proteolysis of nuclear proteins. Genes Cells 3:297-306

10. Nicholson DW (1996) ICE/CED3-like proteases as therapeutic targets for the control of inappropriate apoptosis. Nat. Biotechnol. 14: 297-301

11. Darzynkiewicz Z and Traganos F (1998) Measurement of apoptosis. Adv. Biochem. Eng. Biotechnol. 62: 33-73

12. Misteli T and Spector DL (1997) Applications of the green fluorescent protein in cell biology and biotechnology. Nat. Biotechnol. 15: 961-964

13. Tsien RY (1998) The green fluorescent protein. Annu. Rev. Biochem. 67: 509 544

14. PollokBA and Heim R(1999) Using GFP in FRET-based applications [In Process Citation]. Trends Cell. Biol. 9: 57-60

15. Mitra RD, Silva CM and Youvan DC (1996) Fluorescence resonance energy transfer between blue-emitting and red-shifted excitation derivatives of the green fluorescent protein. Gene 173: 13-17

16. Heim R and Tsien RY (1996) Engineering green fluorescent protein for improved brightness, longer wavelengths and fluorescence resonance energy transfer. Curr. Biol. 6: 178-182
17. Xu X, Gerard AL, Huang BC, Anderson DC, Payan DG and Luo Y (1998) Detection of programmed cell death using fluorescence energy transfer. Nucleic Acids Res. 26: 2034-2035

18. Mahajan NP, Harrison-Shostak DC, Michaux J and Herman B (1999) Novel mutant green fluorescent protein protease substrates reveal the activation of specific caspases during apoptosis. Chem. Biol. 6: 401-409

19. Gossen M, Bonin AL, Freundlieb S and Bujard H (1994) Inducible gene expression systems for higher eukaryotic cells. Curr. Opin. Biotechnol. 5: 516520

20. Lazebnik YA, Kaufmann SH, Desnoyers S, Poirier GG and Earnshaw WC (1994) Cleavage of poly(ADP-ribose) polymerase by a proteinase with properties like ICE. Nature 371: $346-347$

21. Hall JC (1998) Glycine. JPEN J. Parenter. Enteral. Nutr. 22: 393-398

22. Freund C, Ross A, Guth B, Pluckthun A and Holak TA (1993) Characterization of the linker peptide of the single-chain Fv fragment of an antibody by NMR spectroscopy. FEBS Lett. 320: 97-100

23. Steinert PM, Mack JW, Korge BP, Gan SQ, Haynes SR and Steven AC (1991) Glycine loops in proteins: their occurrence in certain intermediate filament chains, loricrins and single-stranded RNA binding proteins. Int. J. Biol. Macromol. 13: 130-139

24. Casciola-Rosen L, Nicholson DW, Chong T, Rowan KR, Thornberry NA, Miller DK and Rosen A (1996) Apopain/CPP32 cleaves proteins that are essential for cellular repair: a fundamental principle of apoptotic death [see comments]. J. Exp. Med. 183: 1957-1964

25. Bossy-WetzelE, NewmeyerDD and Green DR(1998) Mitochondrial cytochrome c release in apoptosis occurs upstream of DEVD-specific caspase activation and independently of mitochondrial transmembrane depolarization. EMBO J. 17: $37-49$

26. Janicke RU, $\mathrm{Ng} \mathrm{P}$, Sprengart ML and Porter AG (1998) Caspase-3 is required for alpha-fodrin cleavage but dispensable for cleavage of other death substrates in apoptosis. J. Biol. Chem. 273: 15540-15545

27. Marks N, Berg MJ, Guidotti A and Saito M (1998) Activation of caspase-3 and apoptosis in cerebellar granule cells. J. Neurosci. Res. 52: 334-341

28. Kozak M (1984) Compilation and analysis of sequences upstream from the translational start site in eukaryotic mRNAs. Nucleic Acids Res. 12: 857-872

29. Rasper DM, Vaillancourt JP, Hadano S, Houtzager VM, Seiden I, Keen SLC Tawa P, Xanthoudakis S, Nasir J, Martindale D, Koop BF, Peterson EP, Thornberry NA, Huang J, Black SC, Hornung F, Leonardo MJ, Hayden M, Roy S and Nicholson DW (1998) Cell death attenuation by 'Usurpin', a mammalian DED-caspase homologue that precludes Caspase-8 recruitment and activation by the CD-95 receptor complex. Cell Death Differ. 5: 271-288

30. Garcia-Calvo M, Peterson EP, Leiting B, Ruel R, Nicholson DW and Thornberry NA (1998) Inhibition of human caspases by peptide-based and macromolecular inhibitors. J. Biol. Chem. 273: 32608-32613 